\title{
Group training on the improvement of college students' career decision-making self-efficacy
}

\author{
Jinliang Wang ${ }^{1,2}$, Dajun Zhang ${ }^{1,2 *}$, Jingjin Shao ${ }^{3}$ \\ ${ }^{1}$ Center for Mental Health Education, Southwest University, Chongqing, China; ${ }^{*}$ Corresponding Author: zhangdj@swu.edu.cn \\ ${ }^{2}$ Research Institute of Educational Science, Southwest University, Chongqing, China \\ ${ }^{3}$ Institute of Developmental Psychology, Beijing Normal University, Beijing, China
}

Received 1 February 2010; revised 18 February 2010; accepted 21 February 2010.

\begin{abstract}
A group training was conducted on 17 college students to improve their career decision-making self-efficacy (CDMSE). The result showed that there was significant difference between the pre-test and the post-test for the experimental group $(n=17)$, whereas no significant difference was found between the pre-test and the posttest for the control group $(n=17)$. In the pre-test, there was no significant difference between the experimental group and the control group, and obvious difference between the two groups was found in the post-test. This indicated that the group training was effective on improving the CDMSE of the college students whose scores of CDMSE were below $27 \%$ point of the total students.
\end{abstract}

Keywords: College Student; Group Training;

Attribution Training;

Career Decision-Making Self-Efficacy

\section{INTRODUCTION}

Career decision-making self-efficacy (CDMSE) is the specific application of self-efficacy theory in the domain of career studies. Based on Bandura's self-efficacy theory and Crites's career maturity theory, Taylor and Betz define CDMSE as the extent to which individuals' believe that they can evaluate themselves, collect career information, select goals, make plans, and resolve problems relevant to career decision-making [1]. It has been found that CDMSE is of great importance to individuals career development. Individuals with higher level of CDMSE tend to be more active and positive in career decision-making, while individuals with lower level of CDMSE tend to be more passive and negative when choosing careers [2-4].
With the reform of college students' employment system in China in late 1990s, college graduates have to make their career choices by themselves, instead of waiting to be distributed by the government. In this situation, students are likely to feel confused and dazed and think that they are not capable of selecting a suitable career for themselves. Under many occasions, many graduates with lower CDMSE choose jobs just for the salary or only based on their parents' views, they usually choose some "hot" jobs beyond their abilities, interests and work values and exclude jobs that are actually in consistent with their abilities and interests. Career decisions made in this way are not mature and often lead to individuals' unsatisfaction with their jobs and other negative emotions, and result in a negative impact on their career development. In addition, individuals with lower CDMSE usually feel anxious and depressed during their career decision- making and their mental health is negatively affected. Therefore, it is urgent and necessary to design intervention which can improve students' decisionmaking self-efficacy.

Group training is a kind of psychological counseling conducted in a group context. Through means of observation, learning and experiencing during interpersonal interaction, group training enables individuals to explore, understand, and accept themselves, improve their interpersonal relationships, acquire new attitudes and behavioral styles, and develop good adaptation abilities. Group training has been found to be an effective way to improve college students' CDMSE [5-8]. In group training, by using such means as helping group members re-experience previous success, verbal persuasion, overcoming the anxiety occurring in career decision-making, providing modeling, and attributional training, counselors assist group members in self-evaluation, career information collection, goal setting, plan making, and solution of problems. However, little empirical studies based on the Chinese reality have been conducted on improving college students' CDMSE, which has blocked 
subsequent studies in the domain of CDMSE. Moreover, existing studies on CDMSE improvement were conducted either by teaching students career decision-making skills or by attributional training, seldom studies have combined the two means. As argued by Borkowski, mere emphasis on individuals' effort is not enough, because great effort can not necessarily lead to progress when individuals are directed by incorrect $\operatorname{cog}$ nitive strategies, which will decrease individuals' confidence [9]. Borkowski's statement has implied the importance of both internal attribution and career decisionmaking skills. Therefore, in this study, we consider the combination of attributional training and skills acquirement to improve college students' career decision-making self-efficacy.

\section{METHOD}

\subsection{Participants}

Students were recruited from the Southwest University in China through poster advertising. Career Decisionmaking Self-efficacy Scale (CDMSE) was administrated to the recruited students [10]. Students' scores on CDMSE scale were used as standard to select participants, 17 students whose scores were below $27 \%$ point of the total students were randomly selected into the experimental group $($ female $=12$, male $=5$ ), and another 17 students with the same condition were selected into the control group $($ female $=12$, male $=5$ ). No significant difference existed between the two groups on CDMSE.

\subsection{Instrument}

\subsubsection{Career Decision-making Self-efficacy Scale}

On the basis of Career Decision-making Self-efficacy Scale by Betz and Taylor, according to the interview and open-ended questionnaire, Peng developed this 39 items Career Decision-making Self-efficacy Scale, which included five dimensions: self-evaluation, information collection, goal selection, plan making, and problem solution [10]. The internal consistent coefficients of each dimension were between .68 and .81 , the internal consistent coefficient of the total scale was .94 . The retest reliability of each dimension were between 0.51 and 0.60 , the retest reliability of the total scale was 0.66 .

\subsubsection{Internal verse External Locus of Control Scale}

Individuals' CDMSE was found to be significantly related with their attributional style, with individuals with internal attribution having higher level of CDMSE while external attribution individuals having lower level of CDMSE. Attribution training has been shown to be effec- tive in improving individuals' CDMSE [11-13]. Hence, in this study, we noticed the important role of positive attributional training and used the Internal verse External Locus of Control Scale as an assistant instrument. The Internal verse External Locus of Control Scale including 29 items in this study was developed by Rotter [14]. The score ranged from $0-23$, with higher scores indicting higher level of external locus of control. The internal consistent coefficient was 0.70 .

\subsection{Intervention Program}

The design of the intervention program was based on career decision-making self-efficacy theory by Taylor and Betz [1], while Bandura's self-efficacy theory [15], attribution theory, and other theories relevant to career were also taken into consideration. The whole intervention program can be divided into seven units, with each units owning a specific topic, including 'know about your achievement', 'learn to search career information', 'understand your interest and ability', 'set career goals', 'plan your career', 'overcome difficulties', and 'take job applications'. The group training included the following activities and forms such as brain storm, role play, modeling, verbal persuasion, group discussion, and games, etc. During the group training, the experimenter noticed to provide group members with encouragement and direction, and to help them form positive attribution style. At the end of each session, the group members were asked to summarize their feelings towards the training. The experimenter created an acceptable and supportive atmosphere. Through group activities and interpersonal interaction, the group members could attempt to feel the positive experience, rebuild rational knowledge relevant to career choice, learn career decision-making skills, change their career-decision style from the improper and immature one to the proper and mature one, which can be used in realistic situation and therefore improve group members' CDMSE.

\subsection{Implementation Progress}

As a first step, assign participants into control group and experimental group. Based on the concrete situation of the experimental group members, we made modifications on the initial intervention program in order to make the intervention more goal-directed and specific.

Second, the group training was conducted one session each week, with each session lasting 90 minutes. The participants in the control group received on training.

\subsection{Follow up Study}

The participants in the experimental group were investigated again 3 months after the end of CDMSE group training. 


\section{RESULTS}

Career Decision-making Self-efficacy Scale and Internal verse External Locus of Control Scale were used in the pre-test and post-test. Data were analyzed with SPSS 12.0 software for Windows XP.

The comparison of CDMSE scores on pre-test and post-test between the experimental and control group was made (see Table 1).

As can be seen from Table 1, for the participants in the experimental group, the scores on all the dimensions and on the total scale in the post-test were significant higher than scores in the pre-test $(p<0.001)$. However, for the control group, except on the plan making dimension, no significant difference was found on other dimensions and on total score between the pre-test and the post-test $(p>0.05)$.In the pre-test, no matter on all the dimensions and on total scale, no significant difference was found between the experimental group and the control group. However, in the post-test, the scores on all dimensions and on total scale in the experimental group were significantly higher than those in the control groupmembers $(p<0.001)$. This indicated that the ex- perimental group members' CDMSE was significantly improved after the group training.

The comparison of locus of control scores on pre-test and post-test between the experimental and control group was made (see Table 2).

As can be seen from Table 2, for the experimental group, there was a significant difference between the pre-test and post-test on scores of locus of control ( $p<$ 0.01 ), with the post-test scores higher than the pre-test scores. For the control group, no such significant difference was found between the pre-test and the post-test ( $p$ $>0.05)$. In the pre-test, there was no significant difference between the control group and experimental group on the scores of locus of control. But significant difference between the two groups was observed after the group training $(p<0.001)$, which indicated that the group training had significantly improved experimental group members' internal locus of control.

Three months after the group training, another survey of CDMSE using the same scale was conducted on the experimental group members to check up the sustained effects of the group training. The comparison between the scores obtained immediately after the training and the scores obtained three months later was made in Table 3.

Table 1. The comparison of CDMSE scores on pre-test and post-test between the experimental and control group.

\begin{tabular}{|c|c|c|c|c|}
\hline Dimension & Group & Pre-test $(n=17)$ Mean \pm SD & Post-test $(n=17)$ Mean \pm SD & t value \\
\hline & Experimental group & $2.44 \pm 0.46$ & $3.68 \pm 0.63$ & $5.61^{* * *}$ \\
\hline \multirow[t]{3}{*}{ Self-evaluation } & Control group & $2.39 \pm 0.54$ & $2.49 \pm 0.55$ & 2.28 \\
\hline & t value & -.29 & $-5.86^{* * *}$ & \\
\hline & Experimental group & $2.33 \pm 0.42$ & $3.76 \pm 0.57$ & $7.13^{* * *}$ \\
\hline \multirow[t]{3}{*}{ Information collection } & Control group & $2.43 \pm 0.49$ & $2.52 \pm 0.54$ & 2.02 \\
\hline & t value & .18 & $-6.56^{* * *}$ & \\
\hline & Experimental group & $2.12 \pm 0.41$ & $3.56 \pm 0.55$ & $8.62^{* * *}$ \\
\hline \multirow[t]{2}{*}{ Goal setting } & Control group & $2.15 \pm 0.45$ & $2.20 \pm 0.42$ & 2.16 \\
\hline & t value & 0.60 & $-7.45^{* * *}$ & \\
\hline \multirow[t]{3}{*}{ Plan making } & Control group & $2.13 \pm 0.34$ & $2.32 \pm 0.36$ & $4.95^{* * *}$ \\
\hline & t value & .66 & $-6.04^{* * *}$ & \\
\hline & Experimental group & $2.24 \pm 0.37$ & $3.63 \pm 0.56$ & $8.04^{* * *}$ \\
\hline \multirow[t]{3}{*}{ Problem solution } & Control group & $2.31 \pm 0.36$ & $2.41 \pm .45$ & 2.14 \\
\hline & t value & 0.19 & $-7.00^{* * *}$ & \\
\hline & Experimental group & $2.24 \pm 0.33$ & $3.60 \pm 0.51$ & $8.34^{* * *}$ \\
\hline \multirow[t]{2}{*}{ Total scale } & Control group & $2.28 \pm 0.32$ & $2.30 \pm 0.36$ & 2.42 \\
\hline & t value & 0.28 & $-7.89^{* * *}$ & \\
\hline
\end{tabular}

Note: $p<0.05 ;{ }^{\prime} p<0.01 ;{ }^{\cdots} p<0.001$. 
Table 2. The comparison of locus of control scores on pre-test and post-test between the experimental and control group.

\begin{tabular}{lccc}
\hline \multicolumn{1}{c}{ Group } & Pre-test $(\mathrm{n}=17)$ Mean $\pm \mathrm{SD}$ & Post-test $(\mathrm{n}=17)$ Mean $\pm \mathrm{SD}$ & $\mathrm{t}$ value \\
\hline Experimental group & $15.82 \pm 2.834$ & $9.82 \pm 2.32$ & $-19.41^{* * *}$ \\
Control group & $15.41 \pm 1.906$ & $15.59 \pm 2.35$ & 0.24 \\
$\mathrm{t}$ value & -0.497 & $7.20^{* * *}$ & \\
\hline
\end{tabular}

Note: $p<0.05 ; "$ " $p<0.01 ; \cdots p<0.001$.

Table 3. The comparison between the scores obtained immediately after the training and the scores obtained three months later.

\begin{tabular}{lccc}
\hline \multicolumn{1}{c}{ Dimension } & $\begin{array}{c}\text { Immediate after training }(\mathrm{n}=17) \\
\text { Mean } \pm \text { SD }\end{array}$ & $\begin{array}{c}\text { Three months after training }(\mathrm{n}=17) \\
\text { Mean } \pm \mathrm{SD}\end{array}$ & t value \\
\hline Self-evaluation & $3.68 \pm 0.63$ & $3.58 \pm 0.64$ & -1.89 \\
Information collection & $3.76 \pm 0.57$ & $3.67 \pm 0.47$ & -1.93 \\
Goal setting & $3.56 \pm 0.55$ & $3.44 \pm 0.53$ & -2.01 \\
Plan making & $3.40 \pm 0.65$ & $3.43 \pm 0.55$ & -0.67 \\
Problem solution & $3.63 \pm 0.56$ & $3.63 \pm 0.55$ & 0.15 \\
Total scale & $3.60 \pm 0.51$ & $3.58 \pm 0.52$ & -1.52 \\
\hline
\end{tabular}

Note: $p<0.05 ;{ }^{\prime} p<0.01 ;{ }^{\cdots}{ }^{\prime} p<0.001$.

As can be seen from Table 3, no significant difference was found between the scores obtained immediately after the training and the scores obtained three months later, despite a nonsignificant reduce on the dimension of self-evaluation, information collection, goal selection, plan making and on the total score $(p>0.05)$. This indicated that the group training in this study has a sustained effect on the improvement of CDMSE.

\section{DISCUSSIONS}

Group training is an assistant form of education on career development. In this study it was found that group training was effective on the improvement of CDMSE and could facilitate individuals' career planning development. The group members in the experimental group maintained a higher level of CDMSE three months after the group training, showing the efficiency of this group training. The reasons why the group training could achieve success were due to the following aspects.

\subsection{Effective Application of Group Training}

According to the requirement of group training on the number of group members, 17 students were included in each group, in order to guarantee the interaction among the members and the satisfaction of the different needs of group members. With an atmosphere of ease and safety, group training is a process in which group members can explore and exchange ideas on the problems they encounter. The group training in this study allowed the group members to discuss problems relevant to career choosing freely and openly. The group members could get instant reactions, suggestions and directions from both the other group members and the counselors, which enabled them to understand, analyze, explore and evaluate themselves more effectively and accurately and to open up their career development according to their own situation [16]. The counselors were aware of the importance of interaction among group members, which guaranteed a two-way communication. The counselors and group members together drafted rules and goals for the group, which were required to be obeyed by all group members. In addition, the counselors noticed the different requirements of different members. When the group members got together, their feeling of loneliness and alienation could be eliminated. Members in this atmosphere would effectively understand themselves and others and establish their self-confidence. With the interaction context and the ease and safety atmosphere, group members were likely to take part in group activities actively, experience the outcomes resulting from their behavior changes, acquire timely feedback from other members and counselors, and then correct their behaviors. Group members learned skills on dealing with interpersonal relations and skills on problem solution, obtained related experience, and improved their interpersonal communication abilities. Besides, group training on career planning caused the group members realize 
the significance of individual career counseling.

\subsection{Intervention Based on Bandura's Self-efficacy Theory Has Guaranteed the Effectiveness}

As Bandura [15] has pointed out, individuals' self-efficacy is affected by such four factors as personal experience, modeling, verbal persuasion and emotion arousing. In the present group training, Bandura's self-efficacy theory was effectively incorporated into the intervention. Counselors allowed group members to recall their past success experience, provided group members with instant and positive feedback and encouragement, set modeling for them, applied breath relaxation, muscle relaxation, imagination relaxation techniques to help group members overcome the anxiety they experience in group activities.

\subsection{The Comprehensive Application of Various Theories on Career Choosing and Career Development}

The group training in present study was designed under the direction of relevant theories on career development and career choosing, including Holland's career theory, Ginzberg and Super's career development theory, social learning theory by Krumboltz, and social cognitive development theory [16]. In his career theory, Holland has assumed that most people can be divided into the following six types of personalities: realistic type, research type, artistic type, social type, management type and conventional type. He proposes that individuals' career choice should be in consistent with their personality styles. The career development theory by Ginzberg and Super has divided individuals' career development into five stages: growing up stage, exploration stage, establishment stage, maintenance stage, and declining stage. Ginzberg holds that each stage has its own task and individuals should be well aware which stage they are at, which reflects individuals' career maturity degree. Super believes that career choosing is actually individuals' choosing the way to realize their self-conceptions. Individuals are answering the question "who am I" in choosing their careers. The social learning theory by Krumboltz holds that individuals' career choice is influenced by individuals' genetic characteristic, environment condition, experience learned in the past, skills acquired in resolving new tasks and new problems, performance standard, and individuals' career values. Social development theory focuses on individuals' decision-making process, during which five kinds of information processing skills are used, including communication, analyzing, synthesizing, evaluation and execution. When the group training was designed, the theories above were taken into consideration. For instance, in the unit "understand your interests and abilities", Holland's careerpersonality matching theory was applied to help group members understand their career personalities and interests correctly. Ginzberg and Super's theory was employed in this unit to allow group members to answer "Who am I" through means of group discussion and brain storm, in order that group members have an accurate and through understanding on themselves.

\subsection{The Combination of Obtaining Career Decision-making Skills and Attributional Training}

In previous studies, researchers either focused on the acquirement of career decision-making skills or attributional training to improve individuals' CDMSE [5-8,17]. Self-efficacy is individuals' perceived abilities to accomplish certain tasks and is related with individuals' cognition on themselves. Therefore, as a means to change individuals' locus of control, forming positive attribution style through attrubitional training is an important means to help individuals know about their abilities properly. However, as a complicated process, career decision- making is affected by multi-aspect factors. Therefore, if only the lack of effort is attributed as the causes of failure in career decision-making and the skills that are needed during career decision-making are neglected, it is very likely that even individuals with positive attribution style are not able to reach a suitable career choice, which will discourage them and cause them depressed. Based on this consideration, Borkowski [9] proposed that only stress on hard working is not enough under many occasions; individuals who are lack of correct cognitive strategies will hardly make progress and then frustrate themselves. Therefore, in this study we combined the skills training with the attribution training, which made our intervention effective.

\section{LIMITATIONS AND DIRECTIONS FOR FUTURE STUDY}

In spite of the effective function of group training on improving college students' CDMSE in this study, limitations still exist. Only students whose scores were below $27 \%$ point of the total students were selected for the group training, which had limited the significance of this study. Students with high scores of CDMSE should be included in the future study. In addition, the small number of subjects would great reduce the reliability of the results based on objective interview and questionnaire. We recommend that naturalistic observation method can be used in the future study to further validate the effectiveness of group training. 


\section{CONCLUSIONS}

Group training can help college students form positive attribution style and improve their CDMSE. Group training on CDMSE has a sustained effect and can be applied to the career counseling in reality.

\section{ACKNOWLEDGEMENTS}

This study was supported by the fund of Key Project 'Strategies on Cultivating College and Middle School Students' Personality Traits' at Key Humanity Social Science Research Institute in Chongqing.

\section{REFERENCES}

[1] Taylor, K.M. and Betz, N.E. (1998) Applications of self-efficacy theory to the understanding and treatment of career indecision. Journal of Vocational Behavior, 22(1), 63-81.

[2] Luzzo, D.A. (1993) Value of career-decision-making selfefficacy in predicting career-decision-making attitudes and skills. Journal of Counseling Psychology, 40(2), 194197.

[3] Betz, N.E. and Hackett, G. (1981) The relationship of career-related self-efficacy expectations to perceived career options in college women and men. Journal of Counseling Psychology, 28(5), 399-410.

[4] Clement, S. (1987) The self-efficacy expectations and occupational preference of females and males. Journal of Occupational Psychology, 60(3), 257-265.

[5] Krass, L.J. and Hughey, K.F. (1992) The impact of an intervention on career decision-making self-efficacy and career indecision. Professional School Counseling, 2(5), 384-391.

[6] Sullivan, K.B. and Mahalik, J.R. (2000) Increasing career self-efficacy for women: Evaluating a group intervention. Journal of Counseling and Development, 2000, 78(1),
54-62.

[7] Chartrand, M. J. and Rose, M. L. (1996) Career interventions for at-risk populations: Incorporating social cognitive influences. The Career Development Quarterly, 44 (4), 341-353.

[8] Luzzo, D.A. (1996) Attribution retraining increases career decision-making self-efficacy. The Career Development Quarterly, 44(3), 378-385.

[9] Borkowski, J.G., Weyhing, R. and Carr, M. (1988) Effect of attributional retraining on strategy-based reading comprehension in learning-disabled student. Journal of Educational Psychology, 80(1), 46-53.

[10] Peng, Y.X. (2000) Development of career decisionmaking self-efficacy scale. Published Postgraduate Dissertation, Central China Normal University, Wuhan.

[11] Taylor, K.M. and Popma, J. (1990) An examination of the relationships among career decision-making self-efficacy, career salience, locus of control, and vocational indecision. Journal of Vocational Behavior, 37(1), 347- 359.

[12] Rodriguez, M. and Blocher, D. (1988) A comparison of two approaches to enhancing career maturity in Puerto Rican college women. Journal of Counseling Psychology, 35(3), 275-280.

[13] Luzzo, D.A. (1994) Effects of verbal persuasion on the career self-efficacy of college freshmen. California Association for Counseling and Development Journal, 14 (1), 31-34.

[14] Rotter, J.B. (1966) Generalized expectancies of internal versus external control of reinforcements. Psychological Monographs, 80(1), 609-609.

[15] Bandura, A. (1977) Self-efficacy: Towards a unifying theory of behavioral change. Psychological Review, 84 (2), 191-215.

[16] Shen, Z.F. (2000) Psychological counseling on career. Shanghai Educational Press, Shanghai.

[17] Li, B. and Wang, X. (2006) Group training on improving women college students' career decision-making self-efficacy. China Mental Health Journal, 20(11), 765-767. 